\begin{abstract}
(c) (i)
Esta obra está sob o direito de Licença Creative Commons Atribuição 4.0 Internacional.

\section{A SAÚDE MENTAL DO HOMEM: \\ UMA AÇÃO DE RESISTIR}

Betijane Soares de Barros ${ }^{1}$

Cleidejane Soares de Barros ${ }^{2}$

Izeni Teixeira Pimentel ${ }^{3}$

Maria Goretti Fernandes ${ }^{4}$

Wesley dos Santos Lima 5

\section{RESUMO}

A saúde mental dos homens é um tema com bastante relevância científica, pois o homem com passar dos tempos vem sofrendo mudanças constantes. O presente trabalho analisou produções científicas publicadas entre 2015 e 2021, nos sites Scielo e Periódicos Capes, com vista a identificar principais causas dos problemas mentais do homem. Trata-se de uma revisão sistemática integrativa. Os descritores estruturados no DeCS e MeSH. O período de coleta dos dados correu no mês de maio de 2021. Adotaram-se como critérios de inclusão artigo científicos. Enquanto os critérios de exclusão foram artigos que não contemplam a temática em saúde mental do homem. Acredita-se que com novos estudos ocorro um novo direcionamento para a promoção da saúde mental do homem.
\end{abstract}

PALAVRAS-CHAVE: Saúde Mental. Saúde do homem. Doença.

\footnotetext{
${ }^{1}$ bj-sb@hotmail.com

2 dr.csbarros@hotmail.com

3 izenimaecoruja2015@gmail.com

${ }^{4}$ profadragoretti@gmail.com

${ }^{5}$ wesleyecristo@gmail.com
} 


\section{INTRODUÇÃO}

Apesar dos avanços da atualidade, ainda é um tabu falar de saúde mental para homens. O estigma negativo sobre os sentimentos masculinos prevalece, enquanto a condição emocional deteriora. Dessa forma, é necessário discutirmos mais sobre o tema, pois, assim, será possível romper o preconceito instalado, tratar sobre as dificuldades masculinas e ajudar no processo de transformação da sociedade (BATISTA, 2020).

Ao abordarmos sobre o assunto, conseguimos desconstruir ideias machistas e estimular o falar das próprias emoções nos homens, o que contrapõe ao padrão cultural deles somente buscarem ajuda quando a situação já está grave, e isso se buscarem. Durante vários anos escuta-se inúmeras histórias de sofrimento pela falta de diálogo e abertura masculina (ARAVENA, GAJARDO e SAGUEZ, 2018).

A mudança que têm acontecido em relação ao homem, com relação aos seus sentimentos, emoções e tantos outros aspectos, ocorre devido a um processo histórico de rápida transformação do contexto social (CAMPOS, 2019).

Com isso, aumentam-se as responsabilidades e cobranças sobre esse ser, de modo que ele precisa apresentar, além das competências já imposta, habilidades sociais e emocionais que muitas vezes não estão preparados (FRANKLIN, et al. 2017).

Em posto disso, a saúde mental do homem é um tema que precisa ser melhor trabalhado, pois vem sendo motivo de grande preocupação por parte de profissionais, gestores e entidades governamentais (ARAÚJO, PALMA, ARAÚJO, 2017).

O presente trabalho avaliou produções científicas publicadas entre 2015 a 2021, nos sites Scielo e Periódicos Capes com vista a identificar principais causas dos problemas mentais relacionados aos homens. Espera-se que com novos estudos ocorro um novo olhar direcionado a promoção da saúde mental dos homens.

\section{METODOLOGIA}

Trata-se de uma revisão bibliográfica, do tipo sistemática integrativa, que seguiu as seguintes etapas (ver quadro 1): definição do tema; seleção da pergunta norteadora e escolha da estratégia de busca; descritores e bases de dados mais eficazes no levantamento das publicações; escolha dos critérios de inclusão e exclusão; identificação dos estudos pré-selecionados e selecionados por meio da leitura dos agentes indexadores das publicações, como resumos, palavras-chave e títulos, bem como a organização dos estudos pré-selecionados e a identificação dos estudos selecionados; categorização dos 
estudos selecionados, com a elaboração e o uso da matriz de síntese, além da análise das informações; a formação de uma biblioteca individual e a avaliação crítica dos estudos selecionados; análise, interpretação e discussão dos resultados e a apresentação da revisão em formato de artigo, o qual contempla as propostas para estudos futuros.

Quadro 1 - Detalhamento das etapas da Revisão Sistemática Integrativa.

\begin{tabular}{|c|c|c|c|c|}
\hline ETAPA & $\begin{array}{l}\text { TÓPICOS DE CADA } \\
\text { ETAPA }\end{array}$ & \multicolumn{3}{|c|}{ DETALHAMENTO DE CADA TÓPICO } \\
\hline $\mathbf{1}^{\mathrm{a}}$ & Tema & \multicolumn{3}{|c|}{ A saúde mental do homem } \\
\hline & Pergunta norteadora & \multicolumn{3}{|c|}{ Qual a importância de trabalhar saúde mental do homem? } \\
\hline & Objetivo geral & \multicolumn{3}{|c|}{$\begin{array}{c}\text { Identificar as causas dos problemas na saúde mental do } \\
\text { homem }\end{array}$} \\
\hline & Estratégias de busca & \multicolumn{3}{|c|}{$\begin{array}{l}\text { 1. Cruzamento de descritores por meio do operador booleano } \\
\text { AND; } \\
\text { 2. Uso de aspas nos politermos (descritor com mais de um } \\
\text { termo) para que a varredura de artigos científicos } \\
\text { contemplasse o termo exato; } \\
\text { MESH; } \\
\text { 3. Uso de descritores estruturados (codificação) no DECS ou } \\
\text { 4. Uso de metadados (filtros). }\end{array}$} \\
\hline & \multirow{3}{*}{ Bancos de terminologias } & Banco & \multicolumn{2}{|c|}{ Link } \\
\hline & & DeSC & \multicolumn{2}{|c|}{ http://decs.bvs.br/ } \\
\hline & & $\mathrm{MeSH}$ & \multicolumn{2}{|c|}{ https://www.ncbi.nlm.nih.gov/mesh } \\
\hline & \multirow[t]{3}{*}{$\begin{array}{l}\text { Descritores livres e } \\
\text { estruturados }\end{array}$} & Descritor & DeSC (Rę & $\begin{array}{l}\mathrm{MeSH} \\
\text { (Identificador } \\
\text { Único) } \\
\end{array}$ \\
\hline & & Saúde Mental & 2845 & ID: D008603 \\
\hline & & Homem & - & - \\
\hline & String de busca & \multicolumn{3}{|c|}{ "saúde mental" AND homem } \\
\hline & \multirow{3}{*}{ Site } & \multirow[t]{2}{*}{ Scielo } & \multicolumn{2}{|c|}{ Link } \\
\hline & & & \multicolumn{2}{|c|}{ https://search.scielo.org/ } \\
\hline & & $\begin{array}{l}\text { Periódicos } \\
\text { Capes }\end{array}$ & \multicolumn{2}{|c|}{ https://www-periodicos-capes-gov-br } \\
\hline \multirow[t]{3}{*}{$2^{\mathbf{a}}$} & $\begin{array}{l}\text { Período de coleta dos } \\
\text { dados }\end{array}$ & \multicolumn{3}{|c|}{ Maio de 2021} \\
\hline & Critérios de inclusão & \multicolumn{3}{|c|}{$\begin{array}{l}\text { 1. Texto (artigo científico). } \\
\text { 2. Publicação (2016-2021). }\end{array}$} \\
\hline & Critérios de exclusão & \multicolumn{3}{|c|}{ 1. Artigos que não contemplam a temática. } \\
\hline $3^{\mathbf{a}}$ & \multicolumn{3}{|c|}{$\begin{array}{l}\text { Número de trabalhos selecionados para revisão sistemática } \\
\text { integrativa a partir da leitura dos agentes indexadores das } \\
\text { publicações (tema, descrição, ementa). }\end{array}$} & 4 \\
\hline $4^{a}$ & \multicolumn{3}{|c|}{$\begin{array}{l}\text { Categorias obtidas com a análise dos documentos } \\
\text { investigados online gratuitos e de livre acesso }\end{array}$} & 2 \\
\hline
\end{tabular}

Fonte: elaborada pelos autores. 


\section{RESULTADOS}

Quadro 2 - Corresponde ao total de documentos disponíveis nas Plataformas
Scielo e Periódicos Capes obtidos por string

de busca.

\begin{tabular}{|c|c|c|c|c|}
\hline String de busca & Bases de dados & $\begin{array}{c}\text { Total de } \\
\text { publicações } \\
\text { sem o filtro }\end{array}$ & $\begin{array}{c}\text { Publicações } \\
\text { disponíveis após } \\
\text { aplicar os filtros }\end{array}$ & $\begin{array}{c}\text { Publicações } \\
\text { aproveitadas na } \\
\text { Revisão Sistemática } \\
\text { Integrativa }\end{array}$ \\
\hline \multirow{2}{*}{$\begin{array}{c}\text { saúde mental" AND } \\
\text { homem }\end{array}$} & Scielo & 28 & 6 & 3 \\
\cline { 2 - 5 } & Periódico Capes & 752 & 284 & 1 \\
\cline { 2 - 5 } & TOTAL & 780 & 290 & 4 \\
\hline
\end{tabular}

Figura: 1

Foram detectadas 780 publicações científicas nos bancos de dados, das quais 290 eram artigos disponíveis após o uso dos filtros, desses foram feitos 4 downloads, que obedeceram aos critérios de inclusão, sendo submetidos às etapas da revisão integrativa.

Quadro 3: - Descrição dos documentos (artigos) de acordo com os critérios de inclusão.

\begin{tabular}{|c|c|c|c|c|}
\hline $\mathbf{N}^{\mathbf{o}}$ & Autor (a) & Tema & Ano & Conclusão \\
\hline 1 & $\begin{array}{l}\text { Eraldo } \\
\text { Carlos } \\
\text { Batista }\end{array}$ & $\begin{array}{l}\text { Experiências } \\
\text { vividas pelo } \\
\text { cônjuge cuidador da } \\
\text { esposa em } \\
\text { tratamento } \\
\text { psiquiátrico. }\end{array}$ & 2020 & $\begin{array}{l}\text { Foi possível, ainda, observar que o papel de } \\
\text { cuidador tem gerado sobrecarga física e } \\
\text { emocional no cônjuge, levando-o a um estado de } \\
\text { sentimento de culpa pelo agravamento da doença } \\
\text { da esposa e, consequentemente, ao seu } \\
\text { adoecimento mental. }\end{array}$ \\
\hline 2 & $\begin{array}{l}\text { José M. } \\
\text { Aravena1 } \\
\text { Jean Gajard } \\
2 \text { Rodrigo } \\
\text { Saguez } 3\end{array}$ & $\begin{array}{l}\text { Salud mental de } \\
\text { hombres mayores } \\
\text { em Chile: una } \\
\text { realidade por } \\
\text { priorizar }\end{array}$ & 2018 & $\begin{array}{c}\text { Asimismo, emerge la urgente necesidad de } \\
\text { diseñar programas de salud que incorporen dicha } \\
\text { consideración de género, para lograr una } \\
\text { adecuada pesquisa y aceptabilidad de las } \\
\text { potenciales intervenciones dirigidas a promover } \\
\text { la salud mental y reducir riesgos en hombres } \\
\text { adultos mayores. }\end{array}$ \\
\hline 3 & $\begin{array}{c}\text { Marcela } \\
\text { Franklin } \\
\text { Salvador de } \\
\text { MendonçaI, } \\
\text { Ana } \\
\text { Bernarda } \\
\text { LudermirII }\end{array}$ & $\begin{array}{l}\text { Violência por } \\
\text { parceiro íntimo e } \\
\text { incidência de } \\
\text { transtorno mental } \\
\text { comum }\end{array}$ & 2017 & $\begin{array}{l}\text { A violência por parceiro íntimo está associada à } \\
\text { incidência de transtornos mentais comuns nas } \\
\text { mulheres. É fundamental o tratamento das } \\
\text { consequências da VPI e o apoio às mulheres na } \\
\text { busca de proteção para si pelos serviços públicos. }\end{array}$ \\
\hline 4 & $\begin{array}{l}\text { Annabelle de } \\
\text { Fátima } \\
\text { Modesto } \\
\text { Vargas } \\
\text { Mauro } \\
\text { Macedo } \\
\text { Campos }\end{array}$ & $\begin{array}{l}\text { A trajetória das } \\
\text { políticas de saúde } \\
\text { mental e de álcool e } \\
\text { outras drogas no } \\
\text { século XX }\end{array}$ & 2019 & $\begin{array}{l}\text { Em um emaranhado de legislações, foram } \\
\text { catalogadas } 33 \text { normas que, após análise, } \\
\text { demonstram o processo de construção das } \\
\text { políticas públicas relacionadas ao uso de álcool e } \\
\text { outras drogas, alterando a lógica repressiva da } \\
\text { justiça e da patologização do uso de drogas e } \\
\text { possibilitando a transição da discussão do terreno }\end{array}$ \\
\hline
\end{tabular}




\begin{tabular}{|l|l|l|l|}
\hline & & & $\begin{array}{c}\text { da segurança para o da saúde pública, mais } \\
\text { especificamente de saúde mental. }\end{array}$ \\
\hline
\end{tabular}

Fonte: Plataformas online Scielo e Periódicos Capes, 2021.

O corpo textual foi analisado por meio da frequência de palavras, que originou a nuvem de palavras (Figura 1) criada na Plataforma online WordArt. Esta ferramenta agrupa e organiza graficamente as palavras-chave evidenciando-as as mais frequentes.

Figura 1: Nuvem de palavras

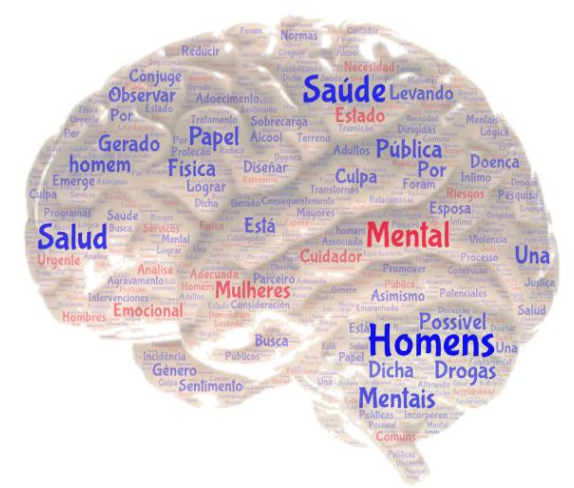

Por meio da Figura 1, foi possível observar que as palavras em evidência na nuvem pertencem as categorias desenvolvidas a partir da análise de conteúdo de Bardin. Todas as categorias derivam da sua frequência (Tabela 1), que diz respeito ao seu quadro referencial. Em consonância ao objetivo deste trabalho, optou-se por descrever as palavras que apresentaram frequência total no texto e, a partir de seus sentidos nos campos textuais, tinham maior relevância para as representações sociais sobre a saúde mental e afastamento dos profissionais da educação, como apresentado na Figura1.

Fonte: autor.

Tabela 1: Frequência das palavras presentes nos artigos coletados nas Plataformas online Scielo e Periódicos Capes.

\begin{tabular}{c|c|c} 
PALAVRAS & FREQUÊNCIA & CATEGORIAS \\
\hline Saúde & 6 & A saúde mental do homem e suas consequências. \\
Mental & 3 & A importância de se trabalhar a saúde mental do \\
Homem & 4 & homem.
\end{tabular}

Fonte: autor. 


\section{DISCUSSÃO}

Os homens necessitam de ações positivas, para fins de facilitar as condições de suas vidas para que possam enfrentar as dificuldades que acarreta no seu dia-a-dia (ARAVENA, GAJARDO e SAGUEZ, 2018).

Podemos observar que essa mudança está de certa forma distante de ocorrer, assim cada vez mais tendo com problemas mentais (MARANGONI et al. 2016).

Seguem abaixo, as categorias temáticas elaboradas a partir da revisão sistemática integrativa.

\section{A SAÚdE MENTAL DO HOMEM E SUAS CONSEQUÊNCIAS}

A saúde mental do homem ainda é proibida ser descultida entre eles, mas que causa consequências graves caso não sejam prevenidos ou tratados. No geral os homens costumam demorar mais para buscar ajuda, principalmente se os sintomas forem associados a transtorno mental (BATISTA, 2020).

É importante desconstruir os preconceitos, como, o de não demonstrar sinal de fraqueza, pois fomos ensinados culturalmente que "homem não chora". Muitos homens se tornam dependentes químicos, principalmente do álcool, em uma tentativa de diminuir certos sintomas, como os da depressão, por exemplo. Com isso, acabam apresentando dois problemas a serem tratados: os mentais e os físicos, tais como doenças cardíacas, do fígado, dentre outras. Por isso, os transtornos mentais em homens necessitam de atenção e precisam também de prevenção (ARAVENA, GAJARDO e SAGUEZ, 2018).

A maioria dos homens tem vergonha de falar sobre seu sofrimento mental, seja por tristeza, ansiedade, insônia, irritabilidade, falta de prazer, desânimo, etc. Consequentemente, deixam de ter uma vida feliz, saudável e com melhor qualidade. Estudos indicam que o principal fator para o homem ter uma boa saúde mental é a qualidade e a manutenção de bons relacionamentos (FRANKLIN, et al. 2017).

Culturalmente, os homens são criados de maneira mais dura, machista, tornam-se oprimidos/opressores, muitas vezes agressivos, não aceitam que podem ser frágeis e sensíveis, tendo uma imagem de que a parte afetiva e emocional não existe. Geralmente, a busca por profissional especialista se dá por um familiar que observa as alterações de comportamento, de humor, no funcionamento da vida diária e nos aspectos profissionais do homem, tornando-se muitas vezes de difícil abordagem e tratamento. Se você 
observar algum sintoma acima, deve procurar ajuda de um médico para diagnosticar e tratar os sintomas adequadamente. De preferência, procure um especialista em saúde mental (CAMPOS, 2019).

Desconhecimento falta de informação, vergonha e até mesmo por questões culturais o homem pode ser levado a não expressar os seus sentimentos para se mostrar sempre forte. Em nossa sociedade, o homem calado que não demonstra sua sensibilidade é muitas vezes considerado viril. Estamos acostumados a ouvir: homem não chora. Isso pode dificultar muitas vezes o autocuidado e o entendimento de que a saúde mental é importante e precisa de atenção. Medo, angústia e ansiedade são sensações que muitas vezes podem levar ao sofrimento na falta de espaço para o desabafo. A falta de abertura, a relutância em se expor, torna a situação dos homens ainda mais difícil e os fazem buscar alternativas que aumentam suas angústias e geram mais sofrimento e desespero (MARANGONI, et al. 2016).

As circunstâncias da atualidade para o homem parecem trazer uma carga emocional maior. Ideias como não prover a família em caso de desemprego, a necessidade de dependência e até a comparação podem provocar sofrimento. Até mesmo na descoberta de doenças graves o homem costuma agir muito mal, ele perde muito tempo guardando a informação e se privando do apoio de familiares e amigos. Esconder os sentimentos não faz bem a ninguém. Uma consequência muito comum é a impotência sexual de origem emocional (MEDEIROS, et al. 2016).

Entre outros fatores, ela está aliada ao estresse, à ansiedade e à baixa autoestima. Como o homem usualmente atribui a sua virilidade à potência sexual, poderá estar ainda mais angustiado com a nova situação. A busca por ajuda geralmente acontece quando o problema já tomou proporções muito grandes e acabou gerando outros, numa verdadeira bola de neve. Os homens raramente conseguem falar de seus problemas com a facilidade que as mulheres têm em falar de temas proibidos. Independentemente do gênero, quando uma pessoa está passando por uma condição de angústia é o momento de buscar ajuda (NEFFA, 2015).

\section{A IMPORTÂNCIA DE SE TRABALHAR A SAÚDE MENTAL DO HOMEM}

Discutir sobre a construção de uma nova masculinidade, que seja mais saudável e capaz de tornar natural para o homem falar de suas emoções. A principal ideia por traz da expressão 
"Homem não chora" é de que o homem não pode apresentar fragilidade ou expor suas emoções. Bem, fica claro nesta proposição uma amostra da masculinidade tóxica e um padrão cultural de sufocar sentimentos. Então, até quando vamos seguir ignorando este silêncio e omitindo que existe uma repressão de emoções? Perpetuar com tal ensinamento somente aumenta a chance de os homens desenvolverem comportamentos destrutivos (ARAÚJO, T. PALMA e ARAÚJO, 2017).

Sendo assim, romper este silêncio é uma forma de aproximá-los de uma afetividade real. Basta observar a qualidade de como é expresso os afetos nas relações sociais, familiares e amorosas. Então, avalie a maturidade emocional dos homens do seu convívio mais íntimo. Essas e outras reflexões precisam ser realizadas de maneira didática para atualizar os homens das novas necessidades e habilidades desta nova era. Consumo de pornografia, sexualidade, assédios, feminicídio, vícios, paternidade e participação da rotina família são somente alguns dos assuntos que precisam ser revistos (CARDOSO, 2015).

Além do desafio mais comum em falar muito pouco dos sentimentos, existem situações de risco capazes de influenciar no surgimento de sintomas prejudiciais à saúde masculina. Tais fatos podem ocorrer por conta de uma visão distorcida que associa adoecimento psíquico como sinal de fraqueza dentro do universo do homem. Sendo assim, é mais comum observar insônia, irritabilidade, isolamento e quadros de depressão, ansiedade, pânico e até suicídio dentro desse quadro (SILVA, 2015).

Nesse sentido, vejamos alguns fatores que podem afetar o sofrimento dos homens, desencadeando riscos para saúde mental (ARAVENA, GAJARDO e SAGUEZ, 2018):

- Doenças graves: podem prejudicar a autonomia da pessoa, o que incorre num declínio da saúde mental;

- Disfunções sexuais: são observados como fator de risco para o aparecimento de complicações mentais e sofrimento psíquico acentuado por afetar diretamente a autoestima;

- Desemprego ou aposentadoria: muitos relatam angústia por não terem uma função social e não se sentirem úteis. Este cenário, associado a isolamento social e pensamentos de desesperança pode contribuir para o surgimento de um quadro psiquiátrico;

- Abuso de álcool e substâncias: se destacam nos serviços de saúde e nas relações familiares como um comportamento que causa inúmeros 
prejuízos, influenciando diretamente na resolução de conflitos de forma agressiva;

- Situações de violência: as diferentes formas de abuso também prejudicam a saúde mental masculina;

- Dentre outras que alterem a rotina subitamente.

Para atuar na prevenção desses problemas, a identificação precoce é fundamental. Dessa forma, ela ajuda na sensibilização para o diálogo e permite a reflexão vinda de pessoas de maior convívio (FRANKLIN, et al. 2017). Caso você identifique o abandono das relações, rotinas e sintomas já descritos, será necessária uma conversa séria, pois, na maioria das vezes, é o familiar que percebe o problema e que consegue mostrar para seu ente a necessidade de uma consulta de avaliação (BATISTA, 2020).

De qualquer forma, é importante o envolvido pensar junto com a sua rede de apoio quais são as ações possíveis para minimizar esses fatores. Uma alternativa interessante é a terapia online, pois ela pode auxiliar neste processo de desconstruir a ideia de que os homens não podem demonstrar sentimentos, afinal, falar é parte do remédio para prevenir adoecimentos mais graves (CAMPOS, 2019).

\section{CONCLUSÃO}

$\mathrm{O}$ presente trabalho apontou que a saúde menta do homem mostraram graus elevados de sofrimento mental, muito superior ao esperado. O elevado número de homens com problemas mentais, bem como os fatos de levarem a esses problemas, serem portadores de outras doenças constituíram situações que demonstraram relação estatisticamente significativa com a presença de adoecimento mental.

A saúde mental do homem demonstrou relação positiva com o sofrimento mental, embora não estatisticamente expressiva. Averiguar a necessidade de expandir a investigação, no sentido de melhor compreender o sofrimento mental dos homens, proporcionando subsídios para a produção de alterações significativas, apontando à melhoria de saúde destes, agindo nos processos determinantes do adoecimento e não através da simples medicalização.

A compreensão profunda do adoecimento mental dos homens exige informações dos processos que determinam que ocorrem nos níveis singular, particular e geral, assim como das correlações que se estabelecem entre esses níveis, o que foge do alcance deste trabalho. 


\section{REFERÊNCIAS}

ARAÚJO, T. M.; PALMA, T. D. F.;

ARAÚJO, N. D. C. Work-related mental

health surveillance in Brazil:

Characteristics, difficulties, and challenges.

Ciência e Saúde Coletiva, v. 22, n. 10, p. 3235-3246, 2017.

ARAVENA, J. M.; GAJARDO, J.;

SAGUEZ, R. Salud mental de hombres

mayores en Chile: una realidad por

priorizar. 2018. v. 2015, n. 4, p. 1-5.

BATISTA, E. C. Experiências vividas

pelo cônjuge cuidador da esposa em

tratamento psiquiátrico. Experiences

undergone by the spouse caregiving the

wife in psychiatric treatment. 2020. p. 31-

39.

CAMPOS, M. M. A trajetória das

políticas de saúde mental e de álcool e outras drogas no século $\mathbf{X X}$. The

trajectory of mental health policies and alcohol and other drugs in the twentieth century. p. 1041-1050, 2019.

CARDOSO, M. C. A. et al. Saúde do trabalhador no processo de negociação

coletiva no Brasil. São Paulo:

\section{Departamento Intersindical de}

Estatística e Estudos Socioeconômicos. v.

76, 2015.

FRANKLIN, M. et al. Violência por

parceiro íntimo e incidência de

transtorno mental comum. 2017. p. 1-8.
MARANGONI, V. S. L. et al. Afastamento laboral por transtornos mentais entre os servidores da prefeitura municipal de Manaus: uma análise preliminar. Semina: Ciências Biológicas e da Saúde, v. 37, n. 2, p. 13, 2016.

MEDEIROS, G. T. DE. et al. Educação permanente em saúde mental: Relato de experiência. Interface: Communication, Health, Education, v. 20, n. 57, p. 475483, 2016.

NEFFA, C. J. O trabalho humano e sua centralidade. Ciências do Trabalho, São Paulo, n. 4, p. 7-26, 2015.

SILVA, E. S. Desemprego e desgaste mental: desafio as políticas públicas e aos sindicatos. Ciências do Trabalho, São Paulo, n. 4, p. 89-109, 2015. 